Annika Reintam Blaser

Manu L. N. G. Malbrain

Joel Starkopf

Sonja Fruhwald

Stephan M. Jakob

Jan De Waele

Jan-Peter Braun

Martijn Poeze

Claudia Spies

\section{Gastrointestinal function in intensive care patients: terminology, definitions and management. Recommendations of the ESICM Working Group on Abdominal Problems}

Received: 27 June 2011

Accepted: 20 December 2011

Published online: 7 February 2012

(C) The Author(s) 2012. This article is published with open access at

Springerlink.com

On behalf of the Working Group on Abdominal Problems of the European Society of Intensive Care Medicine (ESICM WGAP).

Electronic supplementary material

The online version of this article (doi:10.1007/s00134-011-2459-y) contains supplementary material, which is available to authorized users.

A. Reintam Blaser $(\bowtie) \cdot$ J. Starkopf Clinic of Anaesthesiology and Intensive Care, University of Tartu, Puusepa 8,

51014 Tartu, Estonia

e-mail: annika.reintam@ut.ee; annika.reintam.blaser@ut.ee

Tel.: +372-5-142281

Fax: +372-5-3318406

A. Reintam Blaser . S. M. Jakob Department of Intensive Care Medicine, University Hospital (Inselspital) and University of Bern, 3010 Bern, Switzerland

M. L. N. G. Malbrain

Intensive Care Unit, Ziekenhuis Netwerk

Antwerpen, ZNA Stuivenberg,

Lange Beeldekensstraat 267,

2060 Antwerpen, Belgium

\section{J. Starkopf}

Clinic of Anaesthesiology and Intensive

Care, Tartu University Hospital,

Puusepa 8, 51014 Tartu, Estonia

\section{S. Fruhwald}

Department of Anaesthesiology and Intensive Care Medicine, Medical

University of Graz, Auenbruggerplatz 29, 8036 Graz, Austria

\section{J. De Waele}

Department of Critical Care Medicine, Ghent University Hospital and Ghent

Medical School, De Pintelaan 185, 9000 Ghent, Belgium

J.-P. Braun - C. Spies

Department of Anaesthesiology

and Intensive Care,

Charité, Universitätsmedizin Berlin, Charitéplatz 1, 10117 Berlin, Germany

\section{Poeze}

Division of Traumatology,

Department of Surgery, Maastricht University Medical Center, P. Debyelaan 25, 6202 AZ Maastricht, The Netherlands

Abstract Purpose: Acute gastrointestinal (GI) dysfunction and failure have been increasingly recognized in critically ill patients. The variety of definitions proposed in the past has led to confusion and difficulty in comparing one study to another. An international working group convened to standardize the definitions for acute GI failure and GI symptoms and to review the therapeutic options. Methods: The Working Group on Abdominal Problems (WGAP) of the European Society of Intensive Care Medicine (ESICM) developed the definitions for GI dysfunction in intensive care patients on the basis of the available evidence and current understanding of the pathophysiology. Results: Definitions for acute gastrointestinal injury (AGI) with its four grades of severity, as well as for feeding intolerance syndrome and GI symptoms (e.g. vomiting, diarrhoea, paralysis, high gastric residual volumes) are proposed. AGI is a malfunctioning of the GI tract in intensive care patients due to their acute illness. AGI grade $\mathrm{I}=$ increased risk of developing GI dysfunction or failure (a self-limiting condition); AGI grade II = GI dysfunction (a condition that requires interventions); AGI grade III = GI failure (GI function cannot be restored with interventions); AGI grade $\mathrm{IV}=$ dramatically manifesting GI failure (a condition that is immediately life-threatening). Current evidence and expert opinions regarding treatment of acute GI dysfunction are provided. Conclusions: State-ofthe-art definitions for GI dysfunction with gradation as well as management recommendations are proposed on the basis of current medical evidence and expert opinion. The WGAP recommends using these definitions for clinical and research purposes.

Keywords Gastrointestinal function . Failure $\cdot$ Symptoms $\cdot$ Feeding intolerance - Intensive care . Definitions · Classification 


\section{Introduction}

More than 10 years ago a round-table conference on gut dysfunction in critical illness concluded that intestinal function is an important determinant in the outcome of patients admitted to the intensive care unit (ICU), but that there is no objective and clinically relevant definition of gastrointestinal (GI) dysfunction in critical illness. In addition, it was stated that the definition developed in the future should grade the severity of dysfunction [1].

The problems in defining GI dysfunction start with defining GI function. Next to the digestive tract, the GI tract also carries out endocrine, immune and barrier functions. The clinical assessment of the impairment of these functions today is more intuitive than objective. Therefore, endocrine, immune and barrier dysfunctions will not be addressed in detail in the present paper.

Several studies have confirmed that GI symptoms are frequent in the ICU with up to $62 \%$ of patients exhibiting at least one GI symptom for at least 1 day [2-4]. There is also increasing evidence that development of GI problems is related to worse outcome in critically ill patients [2, 5-7].

Different definitions for separate GI symptoms have been used. The lack of markers for the measurement of GI function has suppressed studies in this field as well as the assessment of GI dysfunction as an organ failure. Although plasma citrulline and intestinal fatty acid binding protein have been proposed as possible markers for small bowel function [8], their clinical use in diagnosis and management of GI dysfunction is still unclear.

At least partly due to the lack of a formal definition and classification, treatment strategies for GI problems have been difficult to develop and are currently based on experience, rather than evidence.

There is increasing evidence that early protocolized and goal-oriented care can improve organ function and the patients' outcome during critical illness [9-12]. Improving the definition of GI dysfunction as a part of the multiple organ dysfunction syndrome (MODS) and its derived sequential organ failure assessment score (SOFA) [13] will establish the base for setting up the bundle of preventive and therapeutic measures and support the development of novel treatment strategies.

For these reasons, the Working Group on Abdominal Problems (WGAP) as part of the Perioperative Intensive Care (POIC) section of the European Society of Intensive Care Medicine (ESICM) proposes a set of definitions and grading system of GI dysfunction in critical illness that are applicable both for clinical and research purposes.

\section{Methods}

Several key elements were used as a starting point for defining acute GI organ failure. An organ failure was considered as a dichotomous event that is either present or absent, whereas organ dysfunction is a continuum of physiologic derangement [14]. The expression "GI dysfunction" is used to describe the large variety of GI symptoms (diarrhoea, vomiting) and diagnoses (gastroenteritis) outside of the ICU setting; therefore, the expression "acute GI injury" was introduced.

Current definitions and management recommendations (according to Table $1 ;[15]$ ) were developed on the basis of the available evidence and current understanding of the pathophysiology. Definitions serve as expert opinion, with their reasoning given in each "rationale" subsection.

The working method is described in detail in the electronic supplementary file.

\section{Results}

The WGAP suggests using the following terminology and definitions:

1. Gastrointestinal function

The human GI tract has many functions including facilitating digestion to absorb nutrients and water, barrier control to modulate absorption of intraluminal microbes (and their products), endocrine and immune functions. Perfusion, secretion, motility and a coordinated gut-microbiome interaction are prerequisites for an adequate function [16].

It needs to be underlined that because we currently lack the tool or marker to measure GI function we cannot reliably decide about normal GI function in the acute setting.

2. Acute gastrointestinal injury (AGI) and its different grades

Acute GI injury (AGI) is malfunctioning of the GI tract in critically ill patients due to their acute illness. According to severity the following grades of AGI can be distinguished:

Table 1 Grading of the quality of evidence and strength of recommendations

\begin{tabular}{lll}
\hline Quality of evidence & Rationale \\
\hline A & High & RCT or meta-analyses \\
B & Moderate & $\begin{array}{l}\text { Downgraded RCTs or upgraded } \\
\text { observational studies }\end{array}$ \\
C & Low & Well-done observational studies \\
D & Very low & Case series or expert opinion \\
Strength of recommendation & We recommend \\
Grade 1 & Strong & We suggest \\
Grade 2 & Weak & We \\
\hline
\end{tabular}

$R C T$ randomized controlled trial 
2.1 AGI grade I (risk of developing GI dysfunction or failure) - the function of the GI tract is partially impaired, expressed as GI symptoms related to a known cause and perceived as transient.

Rationale Condition is clinically seen as occurrence of GI symptoms after an insult, which expectedly has temporary and self-limiting nature.

Examples Postoperative nausea and/or vomiting during the first days after abdominal surgery, postoperative absence of bowel sounds, diminished bowel motility in the early phase of shock.

Management The general condition is usually improving and specific interventions for GI symptoms are not needed, except the replacement of fluid requirements by intravenous infusions. Early enteral feeding, started within 24-48 $\mathrm{h}$ after the injury, is recommended [17, 18] (grade 1B). The use of drugs impairing GI motility (e.g. catecholamines, opioids) has to be limited whenever possible [19-22] (grade 1C).

2.2 AGI grade II (gastrointestinal dysfunction) - the GI tract is not able to perform digestion and absorption adequately to satisfy the nutrient and fluid requirements of the body. There are no changes in general condition of the patient related to GI problems.

Rationale The condition is characterized by acute occurrence of GI symptoms requiring therapeutic interventions for achievement of nutrient and fluid requirements. This condition occurs without previous GI interventions or is more severe than might be expected in relation to the course of preceding abdominal procedures. Examples Gastroparesis with high gastric residuals or reflux, paralysis of the lower GI tract, diarrhoea, intra-abdominal hypertension (IAH) grade I (intra-abdominal pressure (IAP) $12-15 \mathrm{mmHg}$ ), visible blood in gastric content or stool. Feeding intolerance is present if at least $20 \mathrm{kcal} / \mathrm{kg} \mathrm{BW} /$ day via enteral route cannot be reached within $72 \mathrm{~h}$ of feeding attempt.

Management Measures to treat the condition and to prevent the progression to GI failure need to be undertaken (e.g. treatment of intra-abdominal hypertension [23], grade 1D; or measures to restore the motility function of GI tract, such as prokinetic therapy [24-26], grade 1C). Enteral feeding should be started or continued; in cases of high gastric residuals/reflux or feeding intolerance regular challenges with small amounts of enteral nutrition (EN) should be regularly considered (grade 2D). In patients with gastroparesis, initiation of postpyloric feeding should be considered in this state, when prokinetic therapy is not effective (grade 2D).

2.3 AGI grade III (gastrointestinal failure)-loss of GI function, where restoration of GI function is not achieved despite interventions and the general condition is not improving.

Rationale Clinically seen as sustained intolerance to enteral feeding without improvement after treatment (e.g. erythromycin, postpyloric tube placement), leading to persistence or worsening of MODS.

Examples Despite treatment, feeding intolerance is persisting-high gastric residuals, persisting GI paralysis, occurrence or worsening of bowel dilatation, progression of IAH to grade II (IAP 15-20 $\mathrm{mmHg}$ ), low abdominal perfusion pressure (APP) (below $60 \mathrm{mmHg}$ ). Feeding intolerance is present and possibly associated with persistence or worsening of MODS.

Management Measures to prevent worsening of GI failure are warranted (e.g. monitoring and targeted treatment of IAH [23], grade 1D). Presence of undiagnosed abdominal problem (cholecystitis, peritonitis, bowel ischaemia) should be excluded. The medications promoting GI paralysis have to be discontinued as far as possible [19-22] (grade 1C). Early parenteral feeding (within the first 7 days of ICU stay) supplementary to insufficient enteral nutrition is associated with higher incidence of hospital infections and should be avoided [27] (grade 2B). Challenges with small amounts of EN should be regularly considered (grade 2D).

2.4 AGI grade IV (gastrointestinal failure with severe impact on distant organ function)-AGI has progressed to become directly and immediately lifethreatening, with worsening of MODS and shock. Rationale Situation when AGI has led to an acute critical deterioration of the general condition of the patient with distant organ dysfunction(s).

Examples Bowel ischaemia with necrosis, GI bleeding leading to haemorrhagic shock, Ogilvie's syndrome, abdominal compartment syndrome (ACS) requiring decompression.

Management Condition requires laparotomy or other emergency interventions (e.g., colonoscopy for colonic decompression) for life-saving indications [28-30] (grade 1D). There is no proven conservative approach to resolve this situation.

As differentiation of the acute GI problem from previously existing chronic condition might be very difficult, we suggest using the same definitions also in cases where the condition (e.g. GI bleeding, diarrhoea, etc.) might be due to a chronic GI disease 
(e.g. Crohn's disease). In patients on chronic parenteral feeding, GI failure (equal to AGI III) should be considered chronically present, and no new acute interventions to restore function are indicated. However, monitoring of IAH and exclusion of the new acute abdominal problems should be performed similarly as in AGI grade III management.

\subsection{Primary and secondary AGI}

2.5.1 Primary AGI is associated with primary disease or direct injury to organs of the GI system (first hit).

Rationale Condition may usually be observed early (during the first day) after the insult to the GI system.

Examples Peritonitis, pancreatic or hepatic pathology, abdominal surgery, abdominal trauma, etc.

2.5.2 Secondary AGI develops as the consequence of a host response in critical illness without primary pathology in the GI system (second hit).

Rationale Condition develops without direct insult to the GI tract.

Examples GI malfunction in a patient with pneumonia, cardiac pathology, nonabdominal surgery or trauma, postresuscitation state.

3. Feeding intolerance syndrome (FI)

FI is a general term indicating intolerance of enteral feeding for whatever clinical reason (vomiting, high gastric residuals, diarrhoea, GI bleeding, presence of entero-cutaneous fistulas, etc.).

Rationale Diagnosis is based on complex clinical evaluation. There is no single clear-cut symptom or value that defines FI [31]. Several symptoms are commonly present.

FI should be considered present if at least $20 \mathrm{kcal} /$ $\mathrm{kg} \mathrm{BW/day} \mathrm{via} \mathrm{enteral} \mathrm{route} \mathrm{cannot} \mathrm{be} \mathrm{reached} \mathrm{within}$ $72 \mathrm{~h}$ of feeding attempt or if enteral feeding has to be stopped for whatever clinical reason. FI should not be considered as present if enteral feeding is electively not prescribed or is withheld/interrupted due to procedures. FI in special conditions: in a patient with postpyloric feeding, FI is defined similarly to gastric feeding. If a patient is not fed enterally due to the presence of enteroatmospheric fistulas, FI should be considered present. If the patient undergoes a surgical intervention for ACS or for changing of surgical dressings of an open abdomen, FI should be considered present immediately after surgery unless enteral feeding can be administered.

Management FI requires efforts to maintain/restore GI function: limiting the use of drugs impairing motility, application of prokinetics and/or laxatives [32-34] (grade 1C), and controlling IAP. Challenges with small amounts of EN should be regularly considered. In patients not tolerating enteral feeding, supplemental parenteral nutrition should be considered [35, 36] (grade 2D). Recent data suggest that delay for 1 week with parenteral nutrition enhances recovery when compared to early intravenous feeding [27] (grade 2B).

4. Intra-abdominal hypertension (IAH)

4.1 IAH is present if IAP is found to be $12 \mathrm{mmHg}$ or higher, confirmed by at least two measurements, 1-6 h apart [37].

Rationale Normal IAP is around 5-7 $\mathrm{mmHg}$ [38]. There are inherent variations and fluctuations in the IAP. IAH should also be considered present if the mean of the IAP measurements of the day is $12 \mathrm{mmHg}$ or higher provided that at least four measurements were performed [39].

Management Monitoring of fluid resuscitation is necessary to avoid over-resuscitation [23] (grade 1C). Continuous thoracic epidural analgesia may decrease IAP in postoperative patients with primary IAH [40] (grade 2B). Nasogastric/colonic decompression is suggested for evacuation of intraluminal contents [23] (grade 2D). In patients with intraperitoneal fluids, percutaneous catheter decompression is recommended [23] (grade 1C). Elevation of head of bed above $20^{\circ}$ should be considered as an additional risk for development of IAH [23] (grade 2C). Neuromuscular blockade decreases the IAP [41], but due to many undesirable effects it should be considered only in selected patients (grade 2C).

4.2 Abdominal compartment syndrome (ACS) is defined as a sustained (minimally two standardized measurements, performed $1-6 \mathrm{~h}$ apart) increase in IAP above $20 \mathrm{mmHg}$ with new onset organ failure [37].

Management Although decompression remains the only definite management for ACS, the exact indications and timing of this procedure still remain controversial [42]. Currently it is recommended (1) to perform surgical decompression as a life-saving intervention in patients with ACS that is refractory to other treatment options [28, 43] (grade 1D), and (2) to consider pre-emptive decompression at the time of laparotomy in patients who demonstrate multiple risk factors for IAH/ACS [23] (grade 1D). In most severe cases of ruptured abdominal aortic aneurysm or abdominal trauma the initial use of mesh closure avoids development of ACS [44, 45] (grade 1C). 


\section{Gastrointestinal symptoms}

5.1 Vomiting (emesis) is the occurrence of any visible regurgitation of gastric content irrespective of the amount.

Rationale Vomiting is commonly defined as the oral expulsion of GI contents resulting from contractions of gut and thoracoabdominal wall musculature [46]. Vomiting is contrasted with regurgitation, which is the effortless passage of gastric contents into the mouth [46]. In ICU patients the forcefulness of the act is often not detectable; therefore, regurgitation and vomiting should be assessed together.

Management Several guidelines for prevention and management of postoperative nausea and vomiting are available [47-51]. However, no studies have addressed management of vomiting in mechanically ventilated ICU patients; therefore, no specific recommendation can be given.

5.2 Gastric residual volume could be considered high if a single volume exceeds $200 \mathrm{ml}$ [52-54].

Rationale There is no sufficient scientific evidence or physiological ground to define precise values for high gastric residuals [53, 55]. Measurement of gastric residuals is neither standardized nor validated [56]. It has been suggested that gastric residual volume greater than $200 \mathrm{ml}$ should prompt careful bedside evaluation, but automatic cessation of enteral nutrition solely on the basis on residual volumes of 200-500 ml should be avoided [53, 56, 57]. Despite the lack of scientific evidence, the members of the WGAP arbitrarily use total volumes of gastric residuals above $1,000 \mathrm{ml} /$ $24 \mathrm{~h}$ as a sign of abnormal gastric emptying, which requires specific attention.

Management Intravenous administration of metoclopramide and/or erythromycin is recommended for management of high gastric residuals, whereas cisapride is no longer approved [58] (grade 1B). Routine use of motility agents is not recommended [58] (grade 1A). Acupuncture stimulation may facilitate gastric empting in neurosurgical ICU patients [59] (grade 2B). Use of opioids and deep sedation should be avoided/reduced if possible. Cessation of gastric feeding is suggested if residual volumes exceed $500 \mathrm{ml}$ per single measurement [57]. Here, postpyloric feeding should be considered [58] (grade 2D). Routine application of postpyloric feeding is not advocated [58] (grade 2D). Postpyloric feeding may cause severe small bowel dilatation and perforation in rare cases.
5.3 Diarrhoea is defined as having three or more loose or liquid stools per day with a stool weight greater than 200-250 g/day (or greater then $250 \mathrm{ml} /$ day) [60, 61].

Rationale Normal bowel frequency ranges from three times a week to three times a day. Secretory, osmotic, motor and exudative diarrhoea may be distinguished [61], but in the ICU it is often better to distinguish between disease-, food/feeding- and drug-related diarrhoea [61, 62].

Management Symptomatic therapy-replacement of fluids and electrolytes, haemodynamic stabilization and organ protection (e.g. correction of hypovolaemia to prevent impairment of renal function) forms the basic management $[61,63$, 64] (grade 1D). At the same time, trigger mechanisms need to be discovered and when possible stopped (e.g. laxatives, sorbitol, lactulose, antibiotics) or treated (e.g. malabsorption, inflammatory bowel disease). Feeding-related diarrhoea in critically ill patients may require reduction of infusion rate, repositioning of feeding tube, or dilution of nutrition formula. Changing formula by adding soluble fibre prolongs transit time [61, 64-66] (grade1C). Only in cases of severe or recurrent Clostridium difficileassociated diarrhoea is oral vancomycin superior to metronidazole [67-69] (grade 2C).

5.4 GI bleeding is any bleeding into the GI tract lumen, confirmed by macroscopic presence of blood in vomited fluids, gastric aspirate or stool.

Rationale Asymptomatic, endoscopically evident mucosal damage occurs in the majority of ICU patients [2]. Clinically evident GI bleeding reflecting considerable damage to GI mucosa may be seen in 5-25\% of ICU patients [2]. Clinically important bleeding, defined as overt bleeding in association with haemodynamic compromise or the need for blood transfusions [70], occurs in $1.5-4 \%$ of mechanically ventilated patients $[2,70,71]$.

Management In cases of clinically evident GI bleeding, the haemodynamic status dictates the approach. In cases of bleeding with haemodynamic instability endoscopy is the diagnostic tool of choice [72], but when bleeding is ongoing and massive, precluding adequate endoscopic assessment, angiography is appropriate (grade 2C). Early upper GI endoscopy (less than $24 \mathrm{~h}$ ) is recommended [72, 73] (grade 1A), except for patients with acute variceal bleeding in whom a more expedite procedure (less than $12 \mathrm{~h}$ ) should be considered [74] (grade 2C). Epinephrine injection can be used in combination with 
another method, such as clips, thermocoagulation or sclerosant injection [72] (grade 1A). Routine second endoscopy is not recommended, but in cases of rebleeding, a second attempt for endoscopic therapy is recommended [72] (grade 1A). In cases of a negative upper endoscopy with evidence of GI bleeding, colonoscopy should be performed, followed by small bowel exploration using push enteroscopy if colonoscopy is negative [75] (grade 2C). In cases of ongoing bleeding with negative endoscopies, abdominal surgery with intraoperative endoscopy or interventional radiology should be considered [76, 77] (grade 2C).

5.5 Paralysis of lower GI tract (paralytic ileus) is the inability of the bowel to pass stool due to impaired peristalsis. Clinical signs include absence of stool for three or more consecutive days without mechanical obstruction. Bowel sounds may or may not be present.

Rationale Outside of the ICU, the terms constipation and obstipation include uncomfortable or infrequent bowel movements, hard stool and painful defecation. Because these symptoms may not be expressed in ICU patients, it is suggested to use the term paralysis of lower GI tract. A cutoff level of 3 days has been used in most of the epidemiological ICU studies [78, 79].

Management Inhibitory drugs for GI motility (e.g. catecholamines, sedatives, opioids) must be withdrawn if possible and conditions impairing motility (e.g. hyperglycemia, hypokalaemia) corrected [19-21] (grade 1C). Because of their delayed onset of action, laxative drugs must be started early or given prophylactically [24, 25] (grade 1D).

Because of unknown long-term efficacy and safety the routine use of opioid antagonists cannot be recommended [80, 81] (grade 2B).

Prokinetics like domperidone, metoclopramide and erythromycin are used to stimulate the upper GI tract (stomach and small bowel), whereas neostigmine stimulates small bowel and colonic motility [25, 30]. Despite the lack of wellcontrolled studies and sufficient evidence, we recommend a standardised approach in using prokinetics for management of motility disorders [24, 25] (grade 1D).

\subsection{Abnormal bowel sounds}

Rationale Normal frequency of bowel sounds may range between 5 and 35 sounds/min [82]; the clinical significance of abnormal bowel sounds is not clear. No technique of auscultation has been proven to be superior [83]. The authors suggest auscultation for at least $1 \mathrm{~min}$ in two quadrants, repeated at least once within a tight time frame. Palpation of the abdomen before the auscultation may stimulate peristalsis causing subsequent bowel sounds that may not have been there otherwise [82].

5.6.1 Absent peristalsis-no bowel sounds are heard at cautious auscultation.

Rationale Complete lack of bowel sounds is abnormal [83]. However, it should be recognized that presence of bowel sounds does not confirm normal motility, and that reoccurrence of bowel sounds does not correlate with improvement of paralysis.

5.6.2 Hyperperistalsis is present if excessive bowel sounds are heard on auscultation.

Rationale Hyperperistalsis is a state of excessive motility of the digestive tract. It can be present during bowel obstruction occurring in parts of the bowel as attempts to overcome obstruction [84].

Management There are no special management suggestions for absent/abnormal bowel sounds.

5.7 Bowel dilatation is present if colonic diameter exceeds $6 \mathrm{~cm}$ (greater than $9 \mathrm{~cm}$ for caecum) or small bowel diameter exceeds $3 \mathrm{~cm}$, diagnosed either on plain abdominal X-ray or CT scan [85, 86].

Rationale Bowel dilatation is a common sign in obstruction at any level of the GI tract. Bowel dilatation may also appear without an obstruction; the terms toxic megacolon following colitis and acute colonic pseudo-obstruction or Ogilvie's syndrome, are used to describe acute severe colonic dilatation.

Management Next to the correction of fluid and electrolyte imbalance, nasogastric decompression may be helpful [29, 87] (grade 1D), although routine usage of nasogastric tubes after elective laparotomy is not recommended [88] (grade 1A). After exclusion of mechanical obstruction, intravenous neostigmine could be considered in patients with a caecal diameter $>10 \mathrm{~cm}$ and without improvement within $24 \mathrm{~h}$ [29, 89] (grade 2B). Colonoscopy is recommended for non-surgical decompression in patients with a caecal diameter $>10 \mathrm{~cm}$ and no improvement after $24-48 \mathrm{~h}$ of conservative treatment [29, 87, 90] (grade 1C). Colonoscopic decompression is effective in up to $80 \%$, but carries a certain morbidity/mortality risk [30]. Conservative treatment together with colonoscopy may be continued for $48-72 \mathrm{~h}$ unless the 
caecum is $>12 \mathrm{~cm}$ wide $[30,91]$ (grade 2C). In cases of unresponsiveness to conservative treatment, surgery is indicated due to the threatening risk of perforation [29, 30] (grade 1D). Usage of a laparoscopic technique with thoracic epidural anaesthesia where appropriate enhances bowel function after abdominal surgery [92-94] (grade 1B), and may therefore prevent bowel dilatation.

6. Feeding protocols

Decreased food intake and resulting malnutrition are independent risk factors for in-hospital mortality
[95]. European Society for Parenteral and Enteral Nutrition (ESPEN) guidelines are available with recommendations for nutrition in intensive care [58]. Feeding protocols based on these guidelines should be implemented in every institution. Periods of interruption of enteral feeding due to various interventions in the hospital (surgery, diagnostic or therapeutic interventions, extubation) should be remembered and minimized [96, 97]. Daily assessment of adequacy of enteral nutrition is required.

7. A schematic guideline for the management of patients with AGI is presented in Fig. 1.
Fig. 1 Schematic guideline for the management of patients with AGI. $E F$ enteral feeding, $E N$ enteral nutrition, $P N$ parenteral nutrition

\section{Guideline for diagnosis and management of AGI}

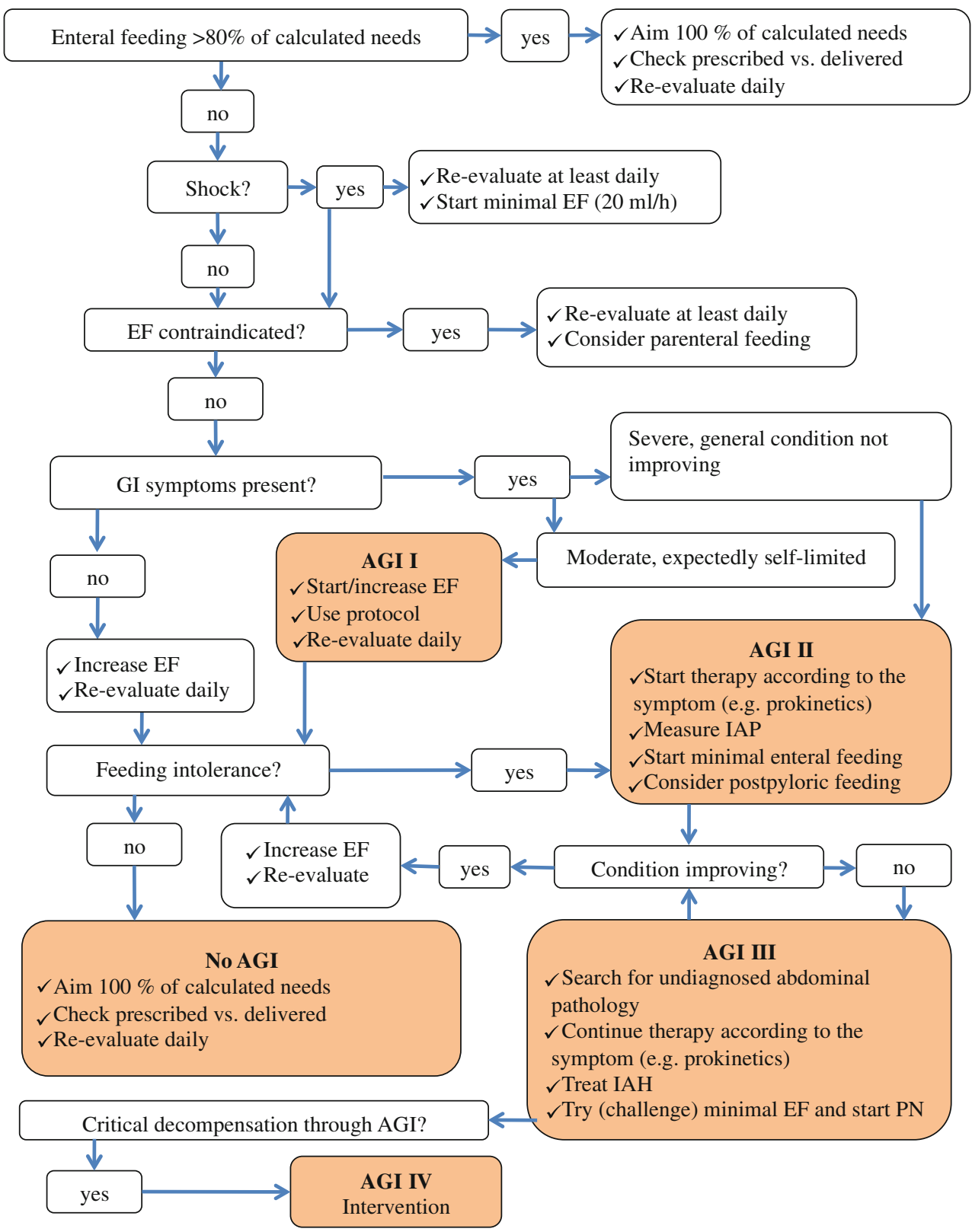




\section{Discussion}

Terminology and definitions provided in the present paper were developed with the aim of providing clinical definitions which may be used in different ICUs and clinical situations.

Our working methods were similar to those commonly used for the consensus definitions and grading of evidence for the treatment recommendations. The main limitation of the current document is the lack of objective measures for GI function/dysfunction. As the evidence in this field is scarce, the definitions are largely based on expert opinion. Therefore, in case new established measures to assess GI function/dysfunction become available, proposed definitions need to be revised. The complete description of diagnostic procedures for conditions underlying AGI is not provided in the current manuscript, common clinical approach is presumed.

Our grading system is not based on a certain numeric variable and is not validated. With no doubt further research is needed to establish the measures of GI function that could be used in a reproducible manner for grading GI function. At present, the descriptions of the grades of AGI are complicated and the same grade of AGI may have different clinical expressions. It is likely that the score will in some extent be dependent on the treatment applied. In fact, other organ dysfunction scores (e.g. SOFA score) have also been developed first, and only validated afterwards. Moreover, the cardiovascular sub-score of SOFA [13], known to be the most performing among all the subscores, is defined as a mean arterial pressure and the usage/ dosage of vasoactive/inotropic agents, where the last part is clearly dependent on the local treatment traditions.

Despite the many well-known limitations which have been restraining the development in this area for so long, we need to move forward, and we suggest to start with the definitions proposed in this paper.

\section{Summary}

The terminology and definitions provided herein should allow better clinical communication as well as comparison between future studies. Defining the specific variables is the first step in a process towards better knowledge in this area. We propose a definition of acute gastrointestinal injury (AGI) with four grades of severity. AGI grade I stands for a self-limiting condition with increased risk of developing GI dysfunction or failure; AGI grade II (GI dysfunction) is a condition requiring interventions to restore GI function; AGI grade III (GI failure) is a condition when GI function cannot be restored with interventions; and AGI grade IV is dramatically manifesting GI failure, which is immediately life-threatening.

The WGAP of ESICM suggests using the proposed definitions until the results of a broader consensus are available. We encourage research to define explicit characteristics of GI function in critically ill patients.

Acknowledgment We thank Luigi Camporota for his contribution.

\section{Conflicts of interest None.}

Open Access This article is distributed under the terms of the Creative Commons Attribution License which permits any use, distribution, and reproduction in any medium, provided the original author(s) and the source are credited.

\section{References}

1. Rombeau JL, Takala J (1997) Summary of round table conference: gut dysfunction in critical illness. Intensive Care Med 23:476-479

2. Mutlu GM, Mutlu EA, Factor P (2001) GI complications in patients receiving mechanical ventilation. Chest 119:1222-1241

3. Reintam A, Parm P, Kitus R, Kern H, Starkopf J (2009) Gastrointestinal symptoms in intensive care patients. Acta Anaesthesiol Scand 53:318-324

4. Montejo JC (1999) Enteral nutritionrelated gastrointestinal complications in critically ill patients: a multicenter study. The Nutritional and Metabolic Working Group of the Spanish Society of Intensive Care Medicine and Coronary Units. Crit Care Med 27:1447-1453
5. Reintam A, Parm P, Kitus R, Starkopf J, Kern H (2008) Gastrointestinal failure score in critically ill patients: a prospective observational study. Crit Care 12:R90

6. Nguyen NQ, Lam SW, Ching K, Chapman M, Fraser RJ, Holloway RH (2007) Gastric feed intolerance is not increased in critically ill patients with type II diabetes mellitus. Intensive Care Med 33:1740-1745

7. Lebuffe G, Vallet B, Takala J, Hartstein G, Lamy M, Mythen M, Bakker J, Bennet D, Boyd O, Webb A (2004) A European multicenter, observational study to assess the value of gastric-toend tidal PCO2 difference in predicting postoperative complications. Anesth Analg 99:166-172
8. Piton G, Manzon C, Cypriani B, Carbonnel F, Capellier G (2011) Acute intestinal failure in critically ill patients: is plasma citrulline the right marker? Intensive Care Med 37:911-917

9. Kumar A, Roberts D, Wood KE, Light B, Parrillo JE, Sharma S, Suppes R, Feinstein D, Zanotti S, Taiberg L, Gurka D, Kumar A, Cheang M (2006) Duration of hypotension before initiation of effective antimicrobial therapy is the critical determinant of survival in human septic shock. Crit Care Med 34:1589-1596

10. Jones AE, Brown MD, Trzeciak S, Shapiro NI, Garrett JS, Heffner AC, Kline JA (2008) The effect of a quantitative resuscitation strategy on mortality in patients with sepsis: a metaanalysis. Crit Care Med 36:2734-2739 
11. Dellinger RP, Levy MM, Carlet JM, Bion J, Parker MM, Jaeschke R, Reinhart K, Angus DC, Brun-Buisson C, Beale R, Calandra T, Dhainaut JF, Gerlach H, Harvey M, Marini JJ, Marshall J, Ranieri M, Ramsay G, Sevransky J, Thompson BT, Townsend S, Vender JS, Zimmerman JL, Vincent JL, International Surviving Sepsis Campaign Guidelines Committee (2008) Surviving sepsis campaign: international guidelines for management of severe sepsis and septic shock: 2008. Crit Care Med 36:296-327

12. ARDS Network (2000) Ventilation with lower tidal volumes as compared with traditional tidal volumes for acute lung injury and the acute respiratory distress syndrome. N Engl J Med 342:1301-1308

13. Vincent JL, Moreno R, Takala J, Willatts S, De Mendonca A, Bruining H, Reinhart CK, Suter PM, Thijs LG (1996) The SOFA (sepsis-related organ failure assessment) score to describe organ dysfunction/failure. On behalf of the Working Group on Sepsis-Related Problems of the European Society of Intensive Care Medicine. Intensive Care Med 22:707-710

14. Bone RC, Balk RA, Cerra FB, Dellinger RP, Fein AM, Knaus WA, Schein RM, Sibbald WJ (1992) Definitions for sepsis and organ failure and guidelines for the use of innovative therapies in sepsis. The ACCP/SCCM Consensus Conference Committee. American College of Chest Physicians/ Society of Critical Care Medicine. Chest 101:1644-1655

15. Schunemann HJ, Jaeschke R, Cook DJ, Bria WF, El-Solh AA, Ernst A, Fahy BF, Gould MK, Horan KL, Krishnan JA, Manthous CA, Maurer JR, McNicholas WT, Oxman AD, Rubenfeld G, Turino GM, Guyatt G, ATS Documents Development Implementation Committee (2006) An official ATS statement: grading the quality of evidence and strength of recommendations in ATS guidelines and recommendations. Am J Respir Crit Care Med 174:605-614

16. Fruhwald S, Kainz J (2010) Effect of ICU interventions on gastrointestinal motility. Curr Opin Crit Care 16:159-164

17. Doig GS, Heighes PT, Simpson F, Sweetman EA, Davies AR (2009) Early enteral nutrition, provided within $24 \mathrm{~h}$ of injury or intensive care unit admission, significantly reduces mortality in critically ill patients: a meta-analysis of randomised controlled trials. Intensive Care Med 35:2018-2027
18. Antonelli M, Azoulay E, Bonten M, Chastre J, Citerio G, Conti G, De Backer D, Lemaire F, Gerlach H, Hedenstierna G, Joannidis M, Macrae D, Mancebo J, Maggiore SM, Mebazaa A, Preiser JC, Pugin J, Wernerman J, Zhang H (2009) Year in review in intensive care medicine 2009: I. Pneumonia and infections, sepsis, outcome, acute renal failure and acid base, nutrition and glycaemic control. Intensive Care Med 36(2):196-209

19. Fruhwald S, Scheidl S, Toller W, Petnehazy T, Holzer P, Metzler H, Hammer HF (2000) Low potential of dobutamine and dopexamine to block intestinal peristalsis as compared with other catecholamines. Crit Care Med 28(8):2893-2897

20. Nguyen NQ, Chapman MJ, Fraser RJ, Bryant LK, Burgstad C, Ching K, Bellon M, Holloway RH (2008) The effects of sedation on gastric emptying and intra-gastric meal distribution in critical illness. Intensive Care Med 34(3):454-460

21. Fruhwald S, Herk E, Petnehazy T, Scheidl S, Holzer P, Hammer F, Metzler H (2002) Sufentanil potentiates the inhibitory effect of epinephrine on intestinal motility. Intensive Care Med 28:74-80

22. McArthur CJ, Gin T, McLaren IM, Critchley JA, Oh TE (1995) Gastric emptying following brain injury: effects of choice of sedation and intracranial pressure. Intensive Care Med 21(7):573-576

23. Cheatham ML, Malbrain ML, Kirkpatrick A, Sugrue M, Parr M, De Waele J, Balogh Z, Leppäniemi A, Olvera C, Ivatury R, D'Amours S, Wendon J, Hillman K, Wilmer A (2007) Results from the international conference of experts on intraabdominal hypertension and abdominal compartment syndrome. II.

Recommendations. Intensive Care Med 33:951-962

24. Fruhwald S, Holzer P, Metzler H (2008) Gastrointestinal motility in acute illness. Wien Klin Wochenschr 120:6-17

25. Herbert MK, Holzer P (2008) Standardized concept for the treatment of gastrointestinal dysmotility in critically ill patients-current status and future concepts. Clin Nutr 27:25-41

26. Nguyen NQ, Chapman M, Fraser RJ, Bryant LK, Burgstad C, Holloway RH (2007) Prokinetic therapy for feed intolerance in critical illness: 1 drug or two? Crit Care Med 35:2561-2567
27. Casaer MP, Mesotten D, Hermans G, Wouters PJ, Schetz M, Meyfroidt G, Van Cromphaut $S$, Ingels $C$, Meersseman P, Muller J, Vlasselaers D, Debaveye Y, Desmet L, Dubois J, Van Assche A, Vanderheyden S, Wilmer A, Van den Berghe G (2011) Early versus late parenteral nutrition in critically ill adults. N Engl J Med 365(6):506-517

28. Balogh Z, Moore FA, Goettler CE, Rotondo MF, Schwab CW, Kaplan MJ (2006) Management of abdominal compartment syndrome. In: Ivatury R, Cheatham M, Malbrain M, Sugrue M (eds) Abdominal compartment syndrome. Landes Bioscience, Georgetown, pp 264-294

29. Saunders MD, Kimmey MB (2005) Systematic review: acute colonic pseudo-obstruction. Aliment Pharmacol Ther 22:917-925

30. De Giorgio R, Barbara G, Stanghellini V, Tonini M, Vasina V, Cola B, Corinaldesi R, Biagi G, De Ponti F (2001) Review article: the pharmacological treatment of acute colonic pseudo-obstruction. Aliment Pharmacol Ther 15:1717-1727

31. Heyland D, Cook DJ, Winder B, Brylowski L, Van deMark H, Guyatt G (1995) Enteral nutrition in the critically ill patient: a prospective survey. Crit Care Med 23:1055-1060

32. MacLaren R, Kuhl DA, Gervasio JM, Brown RO, Dickerson RN, Livingston TN, Swift K, Headley S, Kudsk KA, Lima JJ (2000) Sequential single doses of cisapride, erythromycin, and metoclopramide in critically ill patients intolerant to enteral nutrition: a randomized, placebo-controlled, crossover study. Crit Care Med 28:438-444

33. MacLaren R, Patrick WD, Hall RI, Rocker GM, Whelan GJ, Lima JJ (2001) Comparison of cisapride and metoclopramide for facilitating gastric emptying and improving tolerance to intragastric enteral nutrition in critically III, mechanically ventilated adults. Clin Ther 23:1855-1866

34. Mentec H, Dupont H, Bocchetti M, Cani P, Ponche F, Bleichner G (2001) Upper digestive intolerance during enteral nutrition in critically ill patients: frequency, risk factors, and complications. Crit Care Med 29:1955-1961

35. Thibault R, Pichard C (2010) Parenteral nutrition in critical illness: can it safely improve outcomes? Crit Care Clin 26:467-480

36. Wernerman J (2008) Paradigm of early parenteral nutrition support in combination with insufficient enteral nutrition. Curr Opin Clin Nutr Metab Care 11:160-163 
37. Malbrain ML, Cheatham ML, Kirkpatrick A, Sugrue M, Parr M, De Waele J, Balogh Z, Leppaniemi A, Olvera C, Ivatury R, D'Amours S, Wendon J, Hillman K, Johansson K, Kolkman K, Wilmer A (2006) Results from the international conference of experts on intra-abdominal hypertension and abdominal compartment syndrome. I. Definitions. Intensive Care Med 32:1722-1732

38. De Keulenaer BL, De Waele JJ, Powell B, Malbrain ML (2009) What is normal intra-abdominal pressure and how is it affected by positioning, body mass and positive end-expiratory pressure? Intensive Care Med 35:969-976

39. Malbrain ML, De laet I, Cheatham M (2007) Consensus conference definitions and recommendations on intra-abdominal hypertension (IAH) and the abdominal compartment syndrome (ACS) - the long road to the final publications, how did we get there? Acta Clin Belg Suppl 62:44-59

40. Hakobyan RV, Mkhoyan GG (2008) Epidural analgesia decreases intraabdominal pressure in postoperative patients with primary intra-abdominal hypertension. Acta Clin Belg 63:86-92

41. De Laet I, Hoste E, Verholen E, De Waele JJ (2007) The effect of neuromuscular blockers in patients with intra-abdominal hypertension. Intensive Care Med 33:1811-1814

42. De Waele JJ, Hoste EA, Malbrain ML (2006) Decompressive laparotomy for abdominal compartment syndrome-a critical analysis. Crit Care. 10:R51

43. De Waele J, Desender L, De laet I, Ceelen W, Pattyn P, Hoste E (2010) Abdominal decompression for abdominal compartment syndrome in critically ill patients: a retrospective study. Acta Clin Belg 65-6:396-400

44. Rasmussen TE, Hallett JW, Noel AA, Jenkins G, Bower C, Cherry KJ, Panneton JM, Gloviczki P (2002) Early abdominal closure with mesh reduces multiple organ failure after ruptured abdominal aortic aneurysm repair: guidelines from a 10-year case-control study. J Vasc Surg 35:246-253

45. Mayberry JC, Mullins RJ, Crass RA, Trunkey DD (1997) Prevention of abdominal compartment syndrome by absorbable mesh prosthesis closure. Arch Surg. 132:957-961

46. Fauci AS, Braunwald E, Kasper DL, Hauser SL, Longo DL, Jameson JL, Loscalzo J (eds) (2007) Harrison's principles of internal medicine, 17th edn. McGraw-Hill, USA
47. Apfel CC, Kranke P, Piper S, Rüsch D, Kerger H, Steinfath M, Stöcklein K, Spahn DR, Möllhoff T, Danner K, Biedler A, Hohenhaus M, Zwissler B, Danzeisen O, Gerber H, Kretz FJ (2007) Nausea and vomiting in the postoperative phase. Expert- and evidence-based recommendations for prophylaxis and therapy. Anaesthesist 56:1170-1180

48. Gómez-Arnau JI, Aguilar JL, Bovaira $\mathrm{P}$, Bustos F, De Andrés J, de la Pinta JC, García-Fernández J, López-Alvarez S, López-Olaondo L, Neira F, Planas A, Pueyo J, Vila P, Torres LM (2010) Postoperative nausea and vomiting and opioid-induced nausea and vomiting: guidelines for prevention and treatment. Rev Esp Anestesiol Reanim 57:508-524

49. Diemunsch P (2008) Conference of experts-short text. Management of postoperative nausea and vomiting. French society of anesthesia and resuscitation. Ann Fr Anesth Reanim 27:866-878

50. McCracken G, Houston P, Lefebvre G (2008) Guideline for the management of postoperative nausea and vomiting. J Obstet Gynaecol Can 30(600-7):608-616

51. Gan TJ, Meyer TA, Apfel CC, Chung F, Davis PJ, Habib AS, Hooper VD, Kovac AL, Kranke P, Myles P, Philip BK, Samsa G, Sessler DI, Temo J, Tramèr MR, Vander Kolk C, Watcha M (2007) Society for ambulatory anesthesia guidelines for the management of postoperative nausea and vomiting. Anesth Analg 105:1615-1628

52. White H, Sosnowski K, Tran K, Reeves A, Jones M (2009) A randomised controlled comparison of early postpyloric versus early gastric feeding to meet nutritional targets in ventilated intensive care patients. Crit Care 13:R187

53. McClave SA, Martindale RG, Vanek VW, McCarthy M, Roberts P, Taylor B, Ochoa JB, Napolitano L, Cresci G, The A.S.P.E.N. Board of Directors and the American College of Critical Care Medicine (2009) Guidelines for the provision and assessment of nutrition support therapy in the adult critically ill patient. J Parenter Enteral Nutr 33:277-316

54. Neumann DA, DeLegge MH (2002) Gastric versus small-bowel tube feeding in the intensive care unit: a prospective comparison of efficacy. Crit Care Med 30:1436-1438

55. Hurt RT, McClave SA (2010) Gastric residual volumes in critical illness: what do they really mean? Crit Care Clin 26:481-490
56. McClave SA, Snider HL (2002)

Clinical use of gastric residual volumes as a monitor for patients on enteral tube feeding. J Parenter Enteral Nutr 26:43-48

57. Montejo JC, Minambres E, Bordejé L, Mesejo A, Acosta J, Heras A, Ferré M, Fernandez-Ortega F, Vaquerizo CI, Manzanedo R (2010) Gastric residual volume during enteral nutrition in ICU patients: the REGANE study. Intensive Care Med 36(8):1386-1396

58. Kreymann KG, Berger MM, Deutz NE, Hiesmayr M, Jolliet P, Kazandjiev G, Nitenberg G, van den Berghe G, Wernerman J, Ebner C, Hartl W, Heymann C, Spies C (2006) ESPEN guidelines on enteral nutrition: intensive care. Clin Nutr 25:210-223

59. Pfab F, Winhard M, Nowak-Machen M, Napadow V, Irnich D, Pawlik M, Bein $T$, Hansen E (2011) Acupuncture in critically ill patients improves delayed gastric emptying: a randomized controlled trial. Anesth Analg 112:150-155

60. Lankisch PR, Mahlke R, Lübbers H, Lembcke B, Rösch W (2006) Zertifizierte medizinische fortbildung: leitsymptom diarrhö. Deutsches Ärzteblatt 103:261-269

61. Wiesen P, Van Gossum A, Preiser JC (2006) Diarrhoea in the critically ill. Curr Opin Crit Care 12:149-154

62. Sabol VK (2007) Diarrhea, applying research to bedside practice. AACN Adv Crit Care 1:32-44

63. Pawlowsky SW, Warren CA, Guerrant R (2009) Diagnosis and treatment of acute or persistent diarrhea. Gastroenterology 136:1874-1886

64. Whelan K, Schneider SM (2011) Mechanisms, prevention, and management of diarrhea in enteral nutrition. Curr Opin Gastroenterol 27:152-159

65. Rushdi TA, Pichard C, Khater YH (2004) Control of diarrhoea by fibreenriched diet in ICU patients on enteral nutrition: a prospective randomized controlled trial. Clin Nutr 23:1344-1352

66. Nakao M, Ogura Y, Satake S, Ito I, Iguchi A, Takagi K, Nabeshima T (2002) Usefulness of soluble dietary fibre for the treatment of diarrhoea during enteral nutrition in elderly patients. Nutrition 18:35-39

67. Zar FA, Bakkanagari SR, Moorthi KM, Davis MB (2007) A comparison of vancomycin and metronidazole for the treatment of Clostridium difficileassociated diarrhea, stratified by disease severity. Clin Infect Dis 45:302-307

68. Leffler DA, Lamont JT (2009) Treatment of Clostridium difficileassociated disease. Gastroenterology 136:1899-1912 
69. Aslam S, Hamill RJ, Musher DM (2005) Treatment of Clostridium difficile-associated disease: old therapies and new strategies. Lancet Infect Dis 5:549-557

70. Cook DJ, Fuller HD, Gyatt GH, Marshall JC, Leasa D, Hall R, Winton TL, Rutledge F, Todd TJ, Roy P et al (1994) Risk factors for gastrointestinal bleeding in critically ill patients. Canadian Critical Care Trials Group. N Engl J Med 330:377-381

71. Mayr VD, Duenser MW, Greil V, Jochberger S, Luckner G, Ulmer H, Friesenecker BE, Takala J, Hasibeder WR (2006) Causes and determinants of outcome in critically ill patients. Crit Care 10:R14

72. Barkun AN, Bardou M, Kuipers EJ, Sung J, Hunt RH, Martel M, Sinclair P, International Consensus Upper Gastrointestinal Bleeding Conference Group (2010) International consensus recommendations on the management of patients with nonvariceal upper gastrointestinal bleeding. Ann Intern Med 152:101-113

73. Cooper GS, Chak A, Way LE, Hammar PJ, Harper DL, Rosenthal GE (1999) Early endoscopy in upper gastrointestinal hemorrhage: associations with recurrent bleeding, surgery, and length of hospital stay. Gastrointest Endosc 49:145-152

74. de Franchis R, Baveno V Faculty (2010) Revising consensus in portal hypertension: report of the Baveno $\mathrm{V}$ consensus workshop on methodology of diagnosis and therapy in portal hypertension. J Hepatology 53:762-768

75. Sidhu R, Sanders DS, Morris AJ, McAlindon ME (2008) Guidelines on small bowel enteroscopy and capsule endoscopy in adults. Gut 57:125-136

76. Eriksson LG, Ljungdahl M, Sundbom M, Nyman R (2008) Transcatheter arterial embolisation versus surgery in the treatment of upper gastrointestinal bleeding after therapeutic endoscopy failure. J Vasc Interv Radiol 19:1413-1418
77. Ripoll C, Banares R, Beceiro I, Menchen P, Catalina MV, Echenagusia A, Turegano F (2004) Comparison of transcatheter arterial embolization and surgery for treatment of bleeding peptic ulcer after endoscopic treatment failure. Vasc Interv Radiol 15:447-450

78. Nassar AP Jr, da Silva FM, de Cleva R (2009) Constipation in intensive care unit: incidence and risk factors. J Crit Care 24:630.e9-630.e12

79. Mostafa SM, Bhandari S, Ritchie G, Gratton N, Wenstone R (2003) Constipation and its implications in the critically ill patient. Br J Anaesth 91:815-819

80. McNicol E, Boyce DB, Schumann R, Carr D (2008) Mu-opioid antagonists for opioid induced bowel dysfunction. Cochrane Database Syst Rev CD006332

81. Holzer P (2010) Opioid antagonists for prevention and treatment of opioidinduced gastrointestinal effects. Curr Opin Anaesthesiol 23:616-622

82. Bickley LS, Syilagyi PG (2009) Bates' guide to physical examination and history taking, 10th edn. Lippincott Williams \& Wilkins, Philadelphia

83. Baid H (2009) A critical review of auscultating bowel sounds. Br J Nurs 18:18

84. Kahan S, Miller R, Smith EG (2009) In a page: signs and symptoms, 2nd edn. Lippincott Williams \& Wilkins, Philadelphia

85. Sheth SG, LaMont JT (1998) Toxic megacolon. Lancet 351:509-513

86. Krajewski K, Siewert B, Eisenberg RL (2009) Colonic dilation. AJR Am J Roentgenol 193:363-372

87. Eisen GM, Baron TH, Dominitiz JA, Faigel DO, Goldstein JL, Johanson JF, Mallery JS, Raddawi HM, Vargo JJ, Waring JP, Fanelli RD, WheelerHarbaugh J, Standards of Practice Committee of the American Society for Gastrointestinal Endoscopy (2002) Acute colonic pseudo-obstruction. Gastrointest Endosc 56:789-792
88. Cheatham ML, Chapman WC, Key SP, Sawyers JL (1995) A meta-analysis of selective versus routine nasogastric decompressiom after elective laparotomy. Ann Surg 221:469-478

89. Ponec RJ, Saunders MD, Kimmey MB (1999) Neostigmine for the treatment of acute colonic pseudo-obstruction. N Engl J Med 341:137-141

90. Jetmore AB, Timmcke AE, Gathright JB Jr, Hicks TC, Ray JE, Baker JW (1992) Ogilvie's syndrome: colonoscopic decompression and analysis of predisposing factors. Dis Colon Rectum 35:1135-1142

91. Dorudi S, Berry AR, Kettlewell MG (1992) Acute colonic pseudoobstruction. Br J Surg 79:99-103

92. Johnson MD, Walsh RM (2009) Current therapies to shorten postoperative ileus. Cleveland Clin J Med 76:641-648

93. Jørgensen H, Wetterslev J, Møiniche S, Dahl JB (2000) Epidural local anaesthetics versus opioid-based analgesic regimens on postoperative gastrointestinal paralysis, PONV and pain after abdominal surgery. Cochrane Database Syst Rev 4:CD001893

94. Freise H, Fischer LG (2009) Intestinal effects of thoracic epidural anesthesia. Curr Opin Anaesthesiol 22:644-648

95. Hiesmayr M, Schindler K, Pernicka E, Schuh C, Schoeninger-Hekle A, Bauer P, Laviano A, Lovell AD, Mouhieddine M, Schuetz T, Schneider SM, Singer P, Pichard C, Howard P, Jonkers C, Grecu I, Lingqvist $\mathrm{O}$, The Nutrition Day Team (2009) Decreased food intake is a risk factor for mortality in hospitalised patients: the nutrition day survey 2006. Clin Nutr 28:484-491

96. Rice TW, Swope T, Bozeman S, Wheeler AP (2005) Variation in enteral nutrition delivery in mechanically ventilated patients. Nutrition 21:786-792

97. Schneider JA, Lee YJ, Grubb WR, Denny J, Hunter C (2009) Institutional practices of withholding enteral feeding from intubated patients. Crit Care Med 37:2299-2302 